\title{
Minke whale acoustic behavior and multi-year seasonal and diel vocalization patterns in Massachusetts Bay, USA
}

\author{
Denise Risch ${ }^{1, *}$, Christopher W. Clark ${ }^{2}$, Peter J. Dugan ${ }^{2}$, Marian Popescu ${ }^{2}$, \\ Ursula Siebert $^{3}$, Sofie M. Van Parijs ${ }^{4}$ \\ ${ }^{1}$ Integrated Statistics, Woods Hole, Massachusetts, USA \\ ${ }^{2}$ Bioacoustics Research Program, Cornell Laboratory of Ornithology, Ithaca, New York, USA \\ ${ }^{3}$ Institute for Terrestrial and Aquatic Wildlife Research, University of Veterinary Medicine Hannover, Büsum, Germany \\ ${ }^{4}$ Northeast Fisheries Science Center, Woods Hole, Massachusetts, USA
}

\begin{abstract}
Passive acoustic monitoring (PAM) is a rapidly growing field, providing valuable insights in marine ecology. The approach allows for long-term, species-specific monitoring over a range of spatial scales. For many baleen whales fundamental information on seasonal occurrence and distribution is still missing. In this study, pulse trains produced by the North Atlantic minke whale, a highly mobile and cryptic species, are used to examine its seasonality, diel vocalization patterns and spatial distribution throughout the Stellwagen Bank National Marine Sanctuary (SBNMS), USA. Three and a half years (2006, 2007 to 2010) of near continuous passive acoustic data were analyzed using automated detection methods. Random forests and cluster analyses grouped pulse trains into 3 main categories (slow-down, constant and speed-up), with several subtypes. Slow-down pulse trains were the most commonly recorded call category. Minke whale pulse train occurrence was highly seasonal across all years. Detections were made from August to November, with $88 \%$ occurring in September and October. No detections were recorded in January and February, and only few from March to June. Minke whale pulse trains showed a distinct diel pattern, with a nighttime peak from approximately 20:00 to 01:00 h Eastern Standard Time (EST). The highest numbers of pulse trains were detected to the east of Stellwagen Bank, suggesting that minke whales travel preferably in deeper waters along the outer edge of the sanctuary. These data show that minke whales consistently use Stellwagen Bank as part of their migration route to and from the feeding grounds. Unlike other baleen whales in this area they do not appear to have a persistent year-round acoustic presence.
\end{abstract}

KEY WORDS: Minke whale $\cdot$ Balaenoptera acutorostrata $\cdot$ Vocalizations $\cdot$ Pulse train $\cdot$ Seasonality Diel variation $\cdot$ Passive acoustic monitoring Resale or republication not permitted without written consent of the publisher

\section{INTRODUCTION}

Many mammals live in fluid social networks, where individuals move over long distances and in relation to one another. In such social systems most aspects of behavior, such as maintaining social contact, mate attraction, territorial defense or anti-predator response, are often mediated by acoustic communi- cation (see McComb \& Reby 2005 for a review). Due to natural limitations of light propagation in the marine environment, cetaceans in particular have evolved to rely on sound for many aspects of their lives. For example, most baleen whales use lowfrequency signals that can propagate over large distances for maintaining social contact during long migrations and in social contexts such as mating (e.g. 
Tyack \& Clark 2000). Sound production may also be related to feeding and navigation (e.g. Clark \& Ellison 2004, Stimpert et al. 2007).

In recent years, passive acoustic monitoring (PAM) has become an important tool for monitoring cetaceans. PAM is especially useful in remote areas, during nighttime or adverse weather conditions and in general for species that are difficult to study at sea (e.g. Moore et al. 2006, Mellinger et al. 2007a, Van Parijs et al. 2009). It can generate long-term records of seasonal occurrence and distribution patterns, providing valuable insights into the habitat utilization of vocally active species, their presence in certain areas and when they may be at risk of deleterious anthropogenic impacts (e.g. Gallus et al. 2012, Mussoline et al. 2012). Where detailed knowledge on the vocal behavior of species exists, these new methods can be used effectively in density estimations (e.g. Barlow \& Taylor 2005, Lewis et al. 2007, Marques et al. 2013).

Given the high mobility and wide range of most baleen whale species, it is challenging to gather even elementary data on their ecology. New methods, such as PAM, may therefore provide a great opportunity to collect baseline ecological data, which cannot be acquired through other methods for some species. However, for many baleen whale species, including minke whales Balaenoptera acutorostrata in the North Atlantic, fundamental knowledge on their acoustic behavior is still missing, often rendering it difficult to interpret PAM data appropriately.

Minke whales occur widely throughout the North Atlantic. They range from Baffin Bay to the Caribbean in the western North Atlantic and from the Barents Sea to the west African continental shelf in the eastern North Atlantic (Van Waerebeek et al. 1999, Reilly et al. 2008). In the central North Atlantic pronounced sexual segregation exists on higher latitude feeding grounds, with females occurring farther north off western Greenland and males remaining further south and along the eastern coast of Greenland (Laidre et al. 2009). While there is evidence that minke whales undertake seasonal migrations between feeding and breeding grounds (e.g. Mitchell 1991, Van Waerebeek et al. 1999, Skaug et al. 2004), some individuals may also stay in temperate waters year-round (Macleod et al. 2004). Anderwald et al. (2011) suggest that there may be 2 separate breeding populations in the North Atlantic. However, to date no breeding grounds have been identified, and winter distribution and occurrence of this species is still barely understood.
North Atlantic minke whales are currently listed as a species of least concern under the IUCN Red List (Reilly et al. 2008). The current estimate for the North American east coast is $8987(\mathrm{CV}=0.32)$ individuals (Waring et al. 2012). Nonetheless, the species is still commercially hunted across its summer range (Robards \& Reeves 2011, see also www.iwcoffice.org). In addition, like most species of marine mammals, it is subject to indirect takes in fisheries (Benjamins et al. 2012) and is exposed to a variety of other threats, including ship-strike, chemical and noise pollution, and degradation and loss of habitat. Considering increasingly complex scenarios of human impacts on the marine environment (e.g. Halpern et al. 2008, Davidson et al. 2012) and the lack of distribution and abundance data for North Atlantic minke whales beyond their summer range, there is a clear need for improved monitoring to ensure that healthy populations are maintained across their entire habitat.

Current monitoring and abundance estimates for minke whales are based on visual data (e.g. Skaug et al. 2004, de Boer 2010, Bartha et al. 2011). However, visual detection of this species at sea can be difficult due to its small size and cryptic behavior (e.g. Rankin et al. 2007). Alternative methods, such as PAM, offer a great opportunity to significantly improve studies of the ecology, behavior, distribution and abundance of this species (Oswald et al. 2011).

Minke whales are known to produce a variety of sounds across their range of occurrence. Low-frequency downsweeps, higher frequency clicks and a variety of other sounds have been reported from the Antarctic (Schevill \& Watkins 1972, Leatherwood et al. 1981). More recently, Rankin \& Barlow (2005) attributed the North Pacific 'boing' sounds to this species, and Gedamke et al. (2001) described the distinct 'star wars' vocalization, produced by Australian dwarf minke whales Balaenoptera acutorostrata.

In the North Atlantic, Beamish \& Mitchell (1973) attributed series of clicks in the 5 to $6 \mathrm{kHz}$ range to minke whales, and Edds-Walton (2000) recorded frequency-modulated downsweeps (118 to $80 \mathrm{~Hz}$ ) in the Gulf of St. Lawrence, Canada. Finally, in the Caribbean, Winn \& Perkins (1976) and Mellinger et al. (2000) recorded low-frequency pulse trains with varying interpulse interval (IPI) structure.

Recent advances in statistical methodology enabled estimates of cell density for North Pacific minke 'boing' vocalizations (Marques et al. 2010, Martin et al. 2013). However, in order to convert these call densities to estimates of animal abundance, it is crucial to estimate cue rates reliably (Marques et al. $2010,2013)$. The rate with which animals vocalize 
may vary with call type, sex of calling animal, behavioral state, season, location, group size and level of disturbance (e.g. Croll et al. 2002, Oleson et al. 2007a,b, Parks et al. 2011, Risch et al. 2012). Thus, a better understanding of basic minke whale vocal behavior is necessary to use PAM beyond species presence/absence detection.

In this study, minke whale pulse trains were recorded across $3.5 \mathrm{yr}$ in the Stellwagen Bank National Marine Sanctuary (SBNMS), Massachusetts, USA. Pulse train characteristics were first examined in detail. Using multivariate statistical analyses, different types were then classified and their relative frequency of occurrence analyzed. In addition, an automated detection algorithm was developed to describe seasonal, spatial and diel patterns of pulse train occurrence.

\section{MATERIALS AND METHODS}

\section{Data collection}

Multi-year acoustic data were collected as part of 2 long-term monitoring projects carried out in 2006 and from December 2007 to May 2010 in the SBNMS (Fig. 1) and surrounding waters (see also Hatch et al. 2008, Hatch et al. 2012). Recordings were made using arrays of 9 to 10 marine autonomous recording units (MARUs) (Calupca et al. 2000). Each MARU was equipped with an HTI-94-SSQ hydrophone (High Tech Instruments; sensitivity: $-168 \mathrm{~dB}$ re $1 \mathrm{~V} / \mu \mathrm{Pa}$ ), connected to a pre-amplifier and A/D converter with 12 bit resolution, resulting in an effective system sensitivity of $-151.7 \mathrm{~dB}$ re $1 \mathrm{~V} / \mu \mathrm{Pa}$. All units sampled continuously at a rate of $2000 \mathrm{~Hz}$, yielding an effective analysis bandwidth of 10 to $1000 \mathrm{~Hz}$, with a flat frequency response $( \pm 1 \mathrm{~dB})$ between 55 and $585 \mathrm{~Hz}$. The units were moored 1 to $2 \mathrm{~m}$ above the sea floor in depths ranging from 30 to $100 \mathrm{~m}$. Units were typically deployed for 3 mo at a time and were recovered and redeployed throughout the study period.

\section{Pulse train measurements}

Preliminary seasonal data analyses showed a peak of minke whale pulse train occurrence from late summer into autumn. Therefore, a subsample of the entire dataset, encompassing a total of $44 \mathrm{~d}$ in August, September and October in 2006 and 2008, were reviewed visually and aurally (fast Fourier transformation [FFT] size: 1024 points, 85\% overlap,

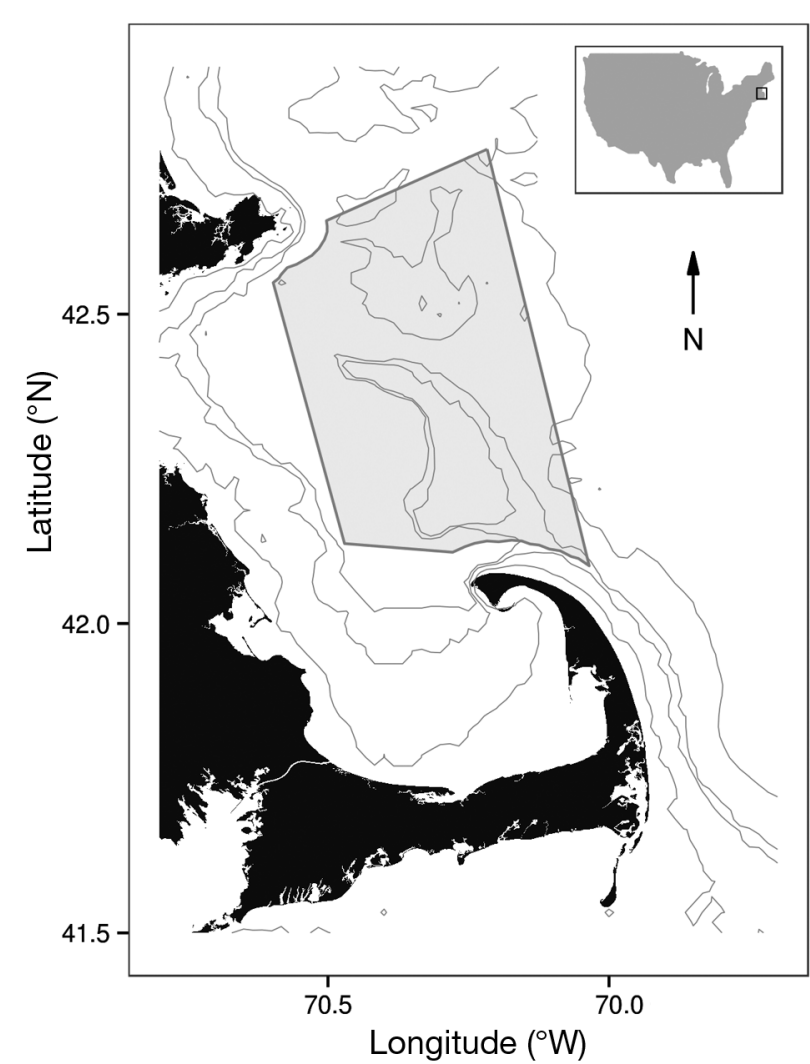

Fig. 1. Gulf of Maine with the Stellwagen Bank National Marine Sanctuary (SBNMS) outlined and shaded in gray. Inset map in upper right corner shows the position of the study area along the US eastern coast

Hanning window), using the sound analysis software XBAT (Figueroa \& Robbins 2008). Good quality (signal-to-noise ratio [SNR] $>10 \mathrm{~dB}$ ), non-overlapping pulse trains were selected for detailed acoustic measurements. In an effort to reduce oversampling of single individuals, not more than 5 pulse trains per hour and a maximum of 40 pulse trains per day were selected for this analysis. Acoustic data were bandpass filtered from 30 to $800 \mathrm{~Hz}$ to remove environmental noise and sounds from other species.

Spectrograms (FFT size: 512 points, 96.9\% overlap, Hanning window, time resolution: $8 \mathrm{~ms}$, frequency resolution: $4 \mathrm{~Hz}$ ) of this subset of data were generated and analyzed with Avisoft-SASLab Pro 5.1 (Avisoft Bioacoustics). The automatic parameter measurement tool was used to measure pulse trains. Individual pulses were detected using an amplitude threshold of -30 to $-55 \mathrm{~dB}$ sound pressure level (SPL) relative to the maximum SPL in the sound file. The threshold was manually adjusted to ensure the detection of every pulse within a pulse train. For each detected pulse, the following parameters were 
measured: start and end time (s), peak, and 1st, 2nd and 3rd quartile frequencies (Hz). Frequency measurements were taken at the start, end and center of the pulse and over the mean spectrum of the pulse. From these measurements, pulse duration (s), interquartile range (IQR) and bandwidth (Hz) were derived. In addition, the following parameters were obtained to characterize the entire pulse train: duration ( $\mathrm{s}$; start of first pulse to end of last pulse), number of pulses, mean IPI ( $\mathrm{s}$; time between starts of 2 consecutive pulses), start and end IPI ( $s$; averaged over the first and last $20 \%$ of pulses, respectively), change in pulse rate (1/IPI $(1 / \mathrm{s})$; difference of averaged values for first and last $20 \%$ ) and change in frequencies over time $\left(\mathrm{Hz}_{\text {; }}\right.$ difference of averaged first and last $20 \%$ mean spectrum measures).

\section{Classification of pulse trains and relative rate of occurrence}

From recordings obtained in the Caribbean, Mellinger et al. (2000) described 2 types of minke whale pulse trains, which differ in IPI structure: the slow-down and the speed-up type. Initial analysis of our data found both of these types, as well as a third, that showed no change in IPI over time. Based on these initial observations, pulse trains were grouped into 1 of 3 categories. Pulse trains were labeled as 'speed-up' if the change in pulse rate was $<-0.5$ and 'slow-down' if it was $>0.5$. If the change in pulse rate was in between these values, pulse trains were labeled as 'constant'.

Subsequently, a supervised random forest model was fitted to the data and the resulting matrix of data dissimilarity was used as input for a fuzzy $c$-means cluster analysis. This multivariate statistical approach was taken to produce a less subjective and reproducible method of vocal repertoire classification, while taking the obvious importance of IPI structure and previous classification based on it into account. Random forests combine predictions of many classification trees, built on random subsets of the data (Breiman et al. 1984, Strobl et al. 2009). The strengths of random forests include high classification accuracy, the availability of methods to assess variable importance and measures of data similarity that allow classification of the original data set (e.g. Cutler et al. 2007). All statistical analyses were conducted using $\mathrm{R}$ v. 2.15 (available at www.Rproject.org). The cforest function in the party package (Strobl et al. 2008) was used for random forest analysis and the number of trees was set to 1000. A total of 30 spectral and temporal predictor variables (see 'Pulse train measurements' above) were included in this analysis. Following suggestions in the literature (e.g. Cutler et al. 2007, Strobl et al. 2009), the number of randomly chosen predictor variables at each split was set to the square root of all available predictor variables $(n=6)$.

The fanny function of the cluster package (Maechler et al. 2012) was used for fuzzy $c$-means clustering and calculating silhouette plots. Fuzzy $c$-means clustering differs from other clustering algorithms in that each observation is assigned to various clusters and the degree of membership is quantified by a coefficient ranging from 0 to 1, with the sum over all clusters being equal to 1 (Kaufman \& Rousseeuw 1990). This method was chosen since it allows for more ambiguity in the data than traditional 'hard' clustering methods and thus proves more realistic in most ecological contexts (e.g. Jackson et al. 2010). The average silhouette width index (Rousseeuw 1987) was used to determine the optimal number of clusters, $k$. The underlying technique determines the association between object $i$ and other members of its cluster and the strength of this association as compared to $i$ 's relation to members from other clusters. The silhouette value $s_{i}$ ranges from -1 to 1 , where 1 indicates that object $i$ fits well within its cluster and -1 that it is not well classified. The average silhouette width of a cluster indicates how tightly grouped the data in the cluster are and the overall average silhouette width is a measure of how well the data is structured. The optimal number of $k$ groups can be found by comparing the silhouette width indices for a range of clustering solutions using different $k s$ and selecting the one yielding the highest average silhouette width, called the silhouette coefficient (SC). It has been suggested that a reasonable structure in the data is found when $\mathrm{SC}>0.5$ and that a strong structure is indicated by SC > 0.7 (Struyf et al. 1996).

In a next step, histograms of IPI for each cluster were calculated and the function mclust of the mclust package (Fraley \& Raftery 2010) was applied to fit Gaussian mixture models in order to describe means and standard deviations of IPI distribution peaks for each cluster.

Finally, the relative frequency of occurrence of each cluster was examined by fully annotating 2 days with peak minke whale pulse train occurrence in 2006 (1 September and 7 October) and 2008 (18 September and 19 September). Each identifiable pulse train was placed in 1 of the clusters and results were plotted as histograms. 


\section{Automatic detection}

Three and a half years $(2006,2007$ to 2010) of data were examined with an automatic detection algorithm that was implemented in a high performance computing (HPC) platform, using custom-built Matlab R2012b scripts (Dugan et al. 2011). The automatic detection consisted of a multi-stage process based on spectrogram intensity binarization, energy projection, feature extraction and classification (Popescu et al. 2013). A set of 18 basic features was extracted from each detected event and passed to a rippledown rule (RIDOR) learner (Gaines \& Compton 1995) for final classification. While the detection stage was designed for general pulse train detection, the RIDOR was trained to identify minke whale pulse trains. However, the RIDOR did not distinguish between the different types of pulse trains as identified in this study.

Performance of the detector was evaluated by creating a truth data set, consisting of minke whale pulse trains mixed with segments of noise. Noise segments were selected to describe typical scenarios of variable seasonal background noise in this region. All pulse trains of the truth data set were scored on a scale of 1 to 4 by their signal quality, with Category 1 calls being of low quality and Category 4 calls appearing clear and well above background noise on the spectrogram. All detection data were post-processed and false positive detections were removed from the final dataset. Post-processing and assembly of the truth data set were performed by an experienced data analyst (D.R.).

\section{Seasonality and diel patterns}

To examine seasonal and diel patterns of pulse train occurrence, 1 channel of each multi-channel dataset was selected for analysis. Channels were selected with the aim to maximize recording time, while keeping a consistent recording location. Due to varying study designs over the years and MARU loss due to trawling, the latter was not always possible. Overall the mean \pm SE distance between 19 different recording locations was $26 \pm 16 \mathrm{~km}(\mathrm{n}=171)$. All data were binned by hour and results plotted by day.

Diel patterns were assessed during the peak season of pulse train occurrence (15 July to 15 November 2006, 2008 and 2009) and only days with detections were used for this analysis. To account for variation in calling rates from one day to the next, mean-adjusted hourly calling rates were calculated by subtracting the average number of detections per day from the number of calls in each hour of the same day (Stafford et al. 2005). Hourly calling rates were then averaged for 3 different light regimes: 'light', 'twilight' and 'dark'. The sun-methods function of the maptools package (Lewin-Koh \& Bivand 2012) was used to determine sun altitude in each hour of analysis for Provincetown, Massachusetts $\left(42.1^{\circ} \mathrm{N}\right.$, $70.2^{\circ} \mathrm{W}$ ), the closest land point to the deployed acoustic recorders. 'Light' periods were defined as those hours with a sun altitude greater than $0^{\circ}$ (approx. 05:30 to 17:00 h Eastern Standard Time, EST), 'twilight' was based on the definition of nautical twilight with sun altitude between $0^{\circ}$ and $-12^{\circ}$ (approx. 04:30 to 05:30 and 17:00 to 18:00 h EST) and 'dark' were those hours, when the altitude of the sun was less than $-12^{\circ}$ (approx.18:00 to 04:30 $\mathrm{h}$ EST). Since the data were not normally distributed (Saphiro-Wilk test), a Kruskal-Wallis test was used to test for differences between light regimes. Wilcoxon rank-sum tests with Bonferroni corrections for multiple testing were used for post-hoc comparisons between pairs of light regimes.

\section{Spatial patterns}

In 2006 MARUs were spaced equally across the SBNMS and recording locations were kept constant throughout the whole year. This dataset was used to examine the spatial distribution of minke whale pulse trains during the peak of their occurrence (15 July to 15 November 2006). For each of the 9 available recording sites the total number of pulse train detections was determined and the data were normalized by the total number of recording days for each site.

\section{RESULTS}

\section{Characterization, classification and relative occurrence}

From the initial $44 \mathrm{~d}$ subsample of the dataset, 396 minke whale pulse trains were selected for detailed analyses. Using the combined approach of supervised random forest and cluster analyses, the best supported grouping of these data resulted in 6 main clusters of pulse trains (Fig. 2). However, the average silhouette width was relatively weak (0.42), suggesting that not all clusters are strongly supported (Kaufman \& Rousseeuw 1990). Thus, distinction between 


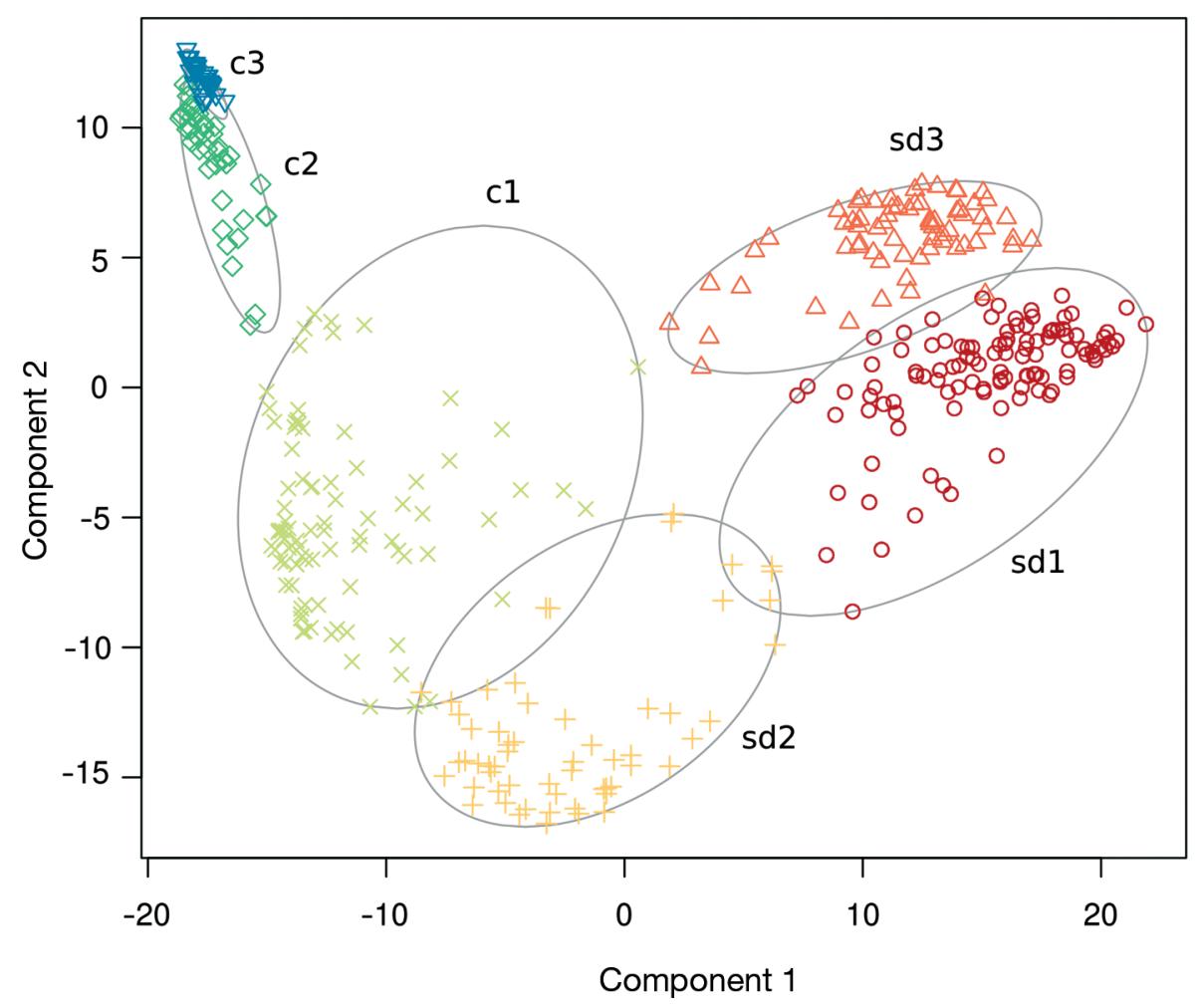

Fig. 2. Bivariate plot of fuzzy cluster analysis results. The 2 components explain $62.76 \%$ of the point variability. Data points represent individual pulse trains and are colored and labeled by pulse train type (c: constant; sd: slow-down), as identified by random forest and cluster analyses

some groups may lie along a gradient of similarity. Temporal features such as IPI at the beginning and end of pulse trains, as well as total pulse train duration, number of pulses and mean IPI, were the most important variables for splitting data into groups.

Based on changes in IPI structure, pulse trains recorded in SBNMS can be split into 3 main categories. While the IPI of slow-down pulse trains (Fig. 3a) increases towards the end of the call, constant pulse trains show a constant IPI throughout the entire duration of the call (Fig. 3b). Speed-up pulse trains, as described by Mellinger et al. (2000), were found in our dataset but in much smaller numbers than the other 2 types. In our sample, they accounted for only 14 out of 396 measured pulse trains and thus did not fall out as a separate cluster. Cluster analysis divided the slow-down and constant pulse trains into 3 subgroups for each type. Table 1 summarizes the basic spectral and temporal measurements for all types of pulse trains that were classified in this study.

In general, slow-down pulse trains were characterized by differences in IPI structure and duration. All calls in this category had a bimodal distribution in IPI. While slow-down types 1 and 2 (sd1 and sd2) showed mean peaks in IPI at about 0.30 and $0.47 \mathrm{~s}$, type 3 (sd3) differed, with mean peaks at 0.42 and 0.70 s. Median total call durations were 35.6 and $39.8 \mathrm{~s}$ for sd1 and sd3, respectively, while sd2 calls were much shorter in duration, with a median of $17.5 \mathrm{~s}$ (Fig. 3a).

Constant pulse trains were subdivided, based primarily on differences in IPI. While constant pulse trains of type 1 (c1) had a mean IPI of $0.39 \mathrm{~s}$, mean IPI for type 2 (c2) and type 3 (c3) were 0.64 and $0.83 \mathrm{~s}$, respectively (Fig. 3b). Median peak frequencies (PF) for all types of slow-down and constant pulse trains were similar and ranged from 106 to $136 \mathrm{~Hz}$, except for c3, which exhibited a lower median PF of $58 \mathrm{~Hz}$. In addition, most types showed an increase in PF throughout the duration of the call. Although highly variable, the median change in PF ranged from 6 to $23 \mathrm{~Hz}$. Type c3 was the only type with a slight decrease $(-5 \mathrm{~Hz})$ in median PF from start to end. With the longest mean IPI and a silhouette width of 0.76 , type c3 was also the most distinct group.

Speed-up pulse trains had a median PF of $106 \mathrm{~Hz}$ and showed a bimodal IPI distribution, decreasing from 0.54 to $0.37 \mathrm{~s}$ throughout the call (Table 1). 

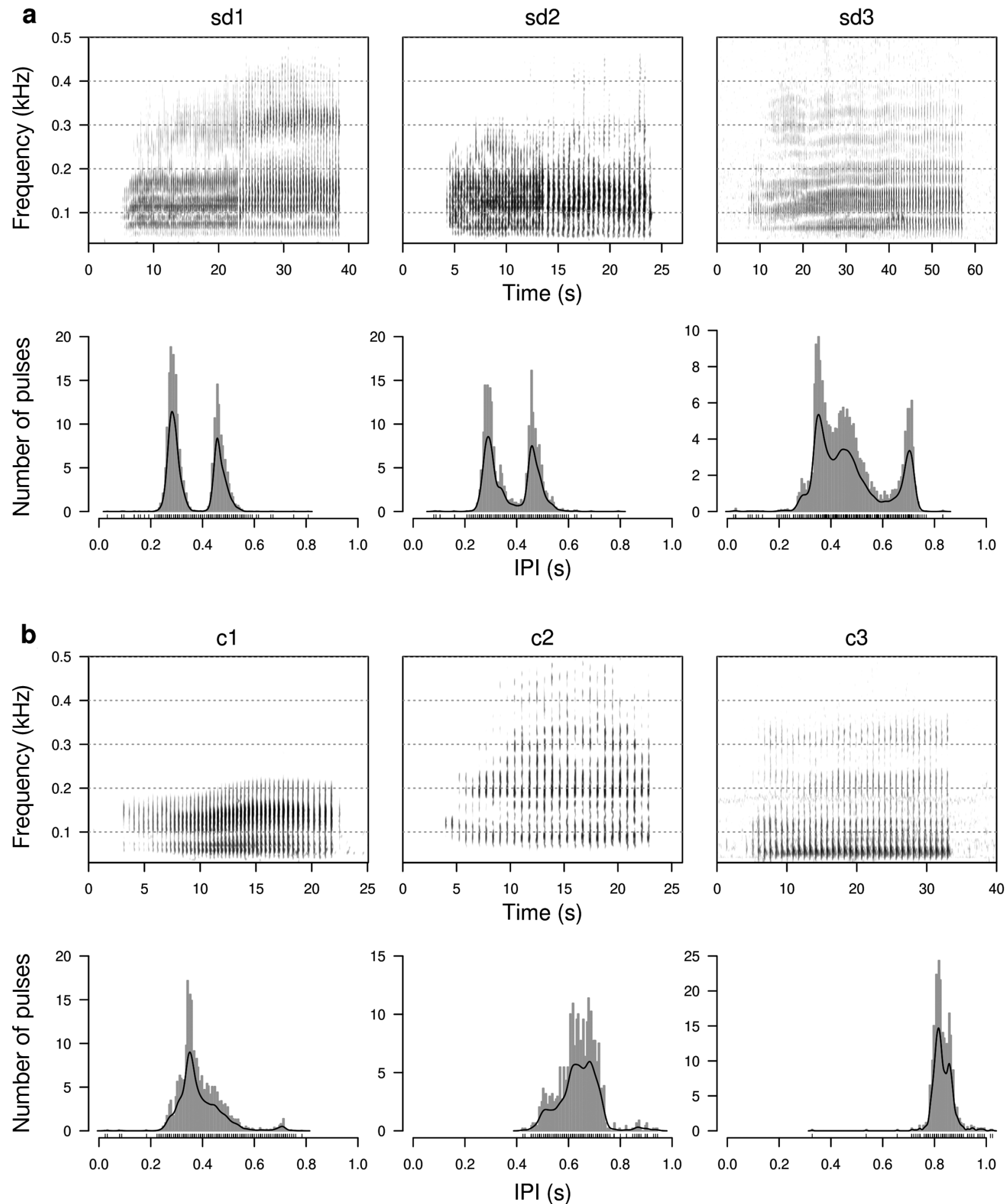

Fig. 3. Spectrograms for (a) slow-down (sd) and (b) constant (c) pulse trains types 1 to 3 and histograms of interpulse interval (IPI). Note the different $x$ - and $y$-axis scales for spectrograms and histograms, respectively. Spectrogram parameters: fast Fourier transform $(\mathrm{FFT})$ size $=512$ points, overlap $=75 \%$, sample rate $=2000$, resolution $=3.9 \mathrm{~Hz}$ and 64 ms. Black lines on histograms indicate fit of Gaussian kernel density functions with bin widths 0.005 for sd1 and c3 and 0.01 for all other plots 
Table 1. Descriptive statistics of minke whale pulse trains recorded in the Stellwagen Bank National Marine Sanctuary (SBNMS). Measurements are median values with 25th and 75th percentiles (in parentheses); interpulse interval (IPI) peaks are mean values $\pm \mathrm{SD}$

\begin{tabular}{|c|c|c|c|c|c|c|c|c|c|c|c|c|}
\hline $\begin{array}{l}\text { Pulse } \\
\text { train } \\
\text { type }\end{array}$ & $\mathrm{n}$ & & $\begin{array}{l}\text { No. of } \\
\text { pulses } \\
\text { (s) }\end{array}$ & $\begin{array}{c}\text { Pulse } \\
\text { train } \\
\text { duration (s) }\end{array}$ & & $\begin{array}{c}\text { Pulse } \\
\text { duration } \\
\text { (s) }\end{array}$ & & $\begin{array}{l}\text { Peak } \\
\text { equency } \\
(\mathrm{Hz})\end{array}$ & $\begin{array}{r}\mathrm{C} \\
\text { in } \\
\text { frequ }\end{array}$ & $\begin{array}{l}\text { Change } \\
\text { n peak } \\
\text { dency }(\mathrm{Hz})\end{array}$ & $\begin{array}{c}\text { 1st IPI } \\
\text { peak (s) }\end{array}$ & $\begin{array}{c}\text { 2nd IPI } \\
\text { peak (s) }\end{array}$ \\
\hline \multicolumn{13}{|c|}{ Slow-down } \\
\hline Type 1 & 109 & 102 & $(87,122)$ & $35.6(30.6,43.9)$ & 0.1 & $(0.09,0.11)$ & 131 & $(126,138)$ & 6 & $(-1,13)$ & $0.29 \pm 0.02$ & $0.47 \pm 0.03$ \\
\hline Type 2 & 58 & 48 & $(30,57)$ & $17.5(11.5,20.9)$ & 0.1 & $(0.08,0.11)$ & 129 & $(121,138)$ & 11 & $(-1,22)$ & $0.30 \pm 0.03$ & $0.47 \pm 0.04$ \\
\hline Type 3 & 68 & 86 & $(74,93)$ & $39.8(35.0,44.1)$ & 0.08 & $(0.07,0.09)$ & 120 & $(116,126)$ & 23 & $(6,33)$ & $0.42 \pm 0.08$ & $0.70 \pm 0.02$ \\
\hline \multicolumn{13}{|l|}{ Constant } \\
\hline Type 1 & 73 & 46 & $(36,58)$ & $17.7(12.5,23.2)$ & 0.07 & $(0.06,0.08)$ & 129 & $(114,133)$ & 15 & $(0,22)$ & $0.39 \pm 0.08$ & - \\
\hline Type 2 & 40 & 20 & $(15,28)$ & $12.6(9.5,17.0)$ & 0.08 & $(0.07,0.09)$ & 136 & $(117,162)$ & 13 & $(-2,47)$ & $0.64 \pm 0.08$ & - \\
\hline Type 3 & 34 & 29 & $(24,38)$ & $23.3(19.4,30.8)$ & 0.12 & $(0.10,0.13)$ & 58 & $(55,61)$ & & $(-10,-1)$ & $0.83 \pm 0.04$ & - \\
\hline Speed-up & 14 & 29 & $(26,38)$ & $12.4 \quad(9.9,18.0)$ & 0.08 & $(0.07,0.09)$ & 106 & $(95,137)$ & 19 & $(-14,31)$ & $0.54 \pm 0.12$ & $0.37 \pm 0.02$ \\
\hline
\end{tabular}
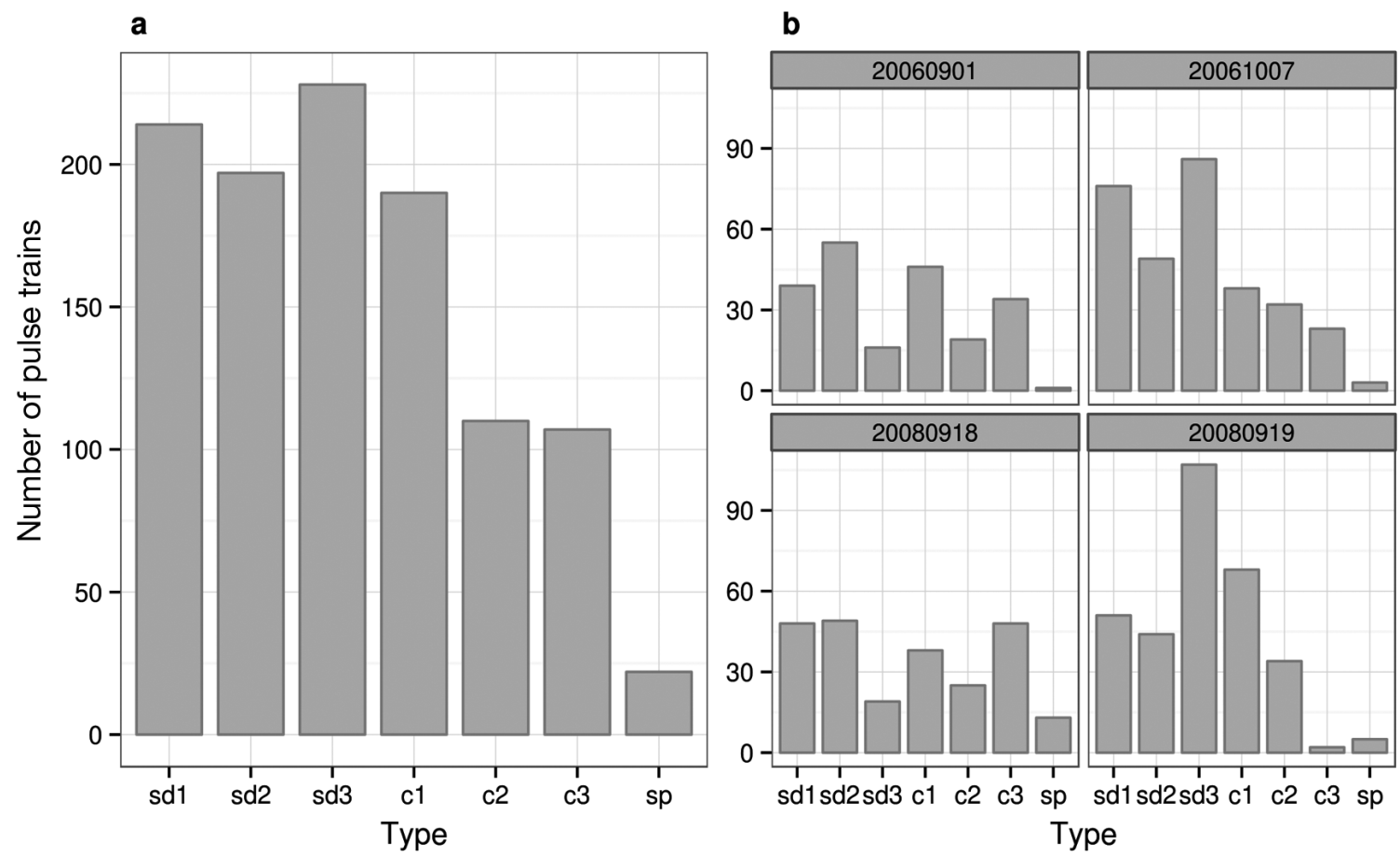

Fig. 4. Frequency distribution of different pulse train types (sd: slow-down; c: constant; sp: speed-up) for 4 randomly sampled days (a) frequency of occurrence over all and (b) split by days. Dates in (b) are given as yyyymmdd

Overall, for all types of pulse trains, most energy was distributed between 50 and $300 \mathrm{~Hz}$.

The pulse train occurrence analysis found all types of identified pulse trains present on each of the 4 selected days (Fig. 4b). The most commonly recorded types were slow-down pulse trains, accounting for $60 \%$ of all pulse trains in this sample ( $\mathrm{n}=1068$ ). While constant pulse trains represented $38 \%$ of the sample, only $2 \%$ were speed-up pulse trains (Fig. 4a). It should be noted that c1 pulse trains, occurred more frequently than the other 2 constant pulse train types. Structurally, this pulse train category lies between slow-down and constant pulse trains, with an overall mean IPI of $0.39 \mathrm{~s}$ (see above) but a few IPIs measured at $0.80 \mathrm{~s}$. Additionally, this group showed some overlap with sd3 (Fig. 2) and had the lowest silhouette width of only 0.3 . 
a

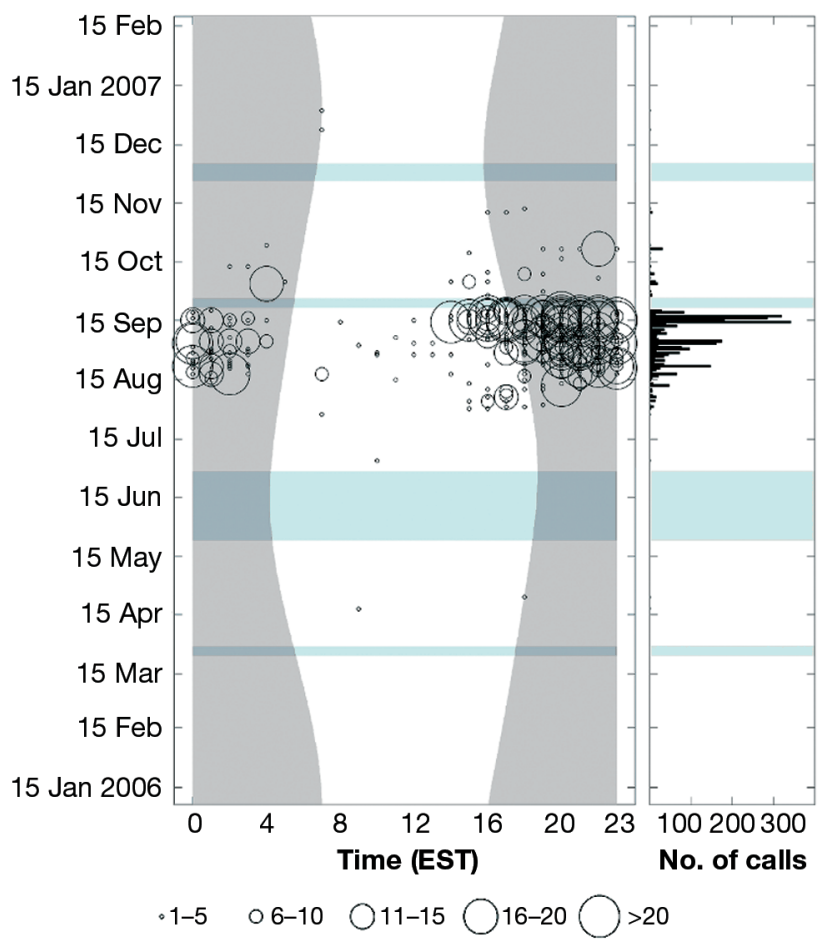

b

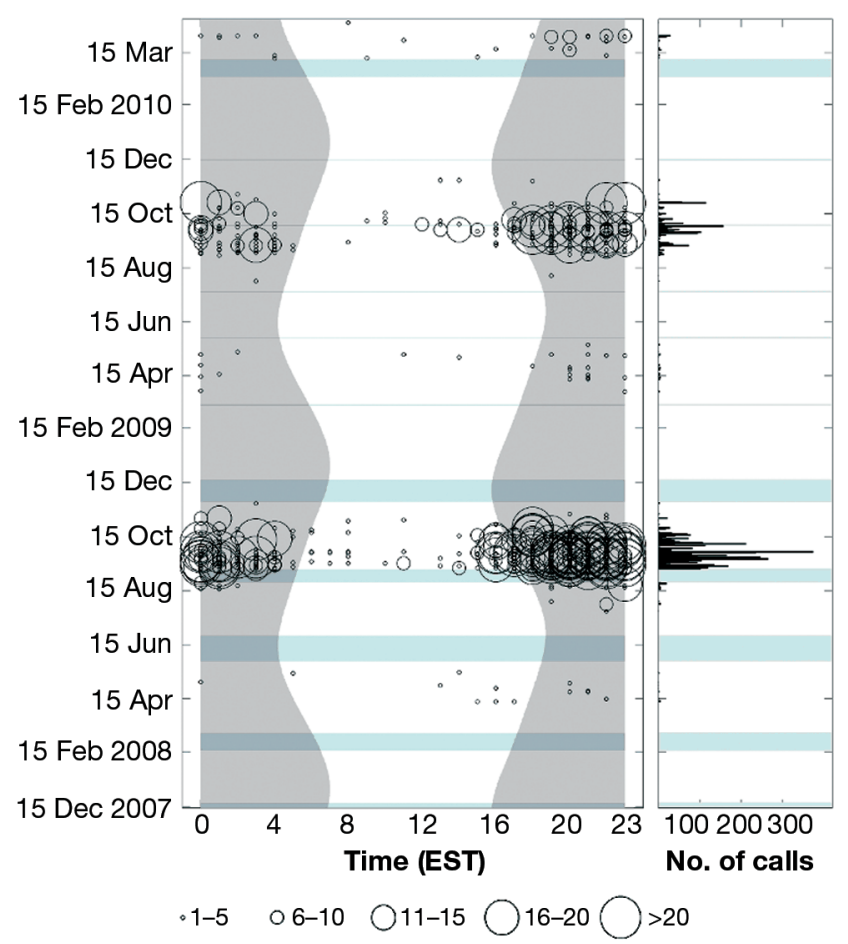

Fig. 5. Seasonal and diel distribution of minke whale pulse trains in (a) 2006 and (b) from December 2007 to March 2010 in the Stellwagen Bank National Marine Sanctuary (SBNMS). Distributions are based on analyses of automatic detection results of 1 channel of data. $Y$-axis shows date; left $X$-axis time of day (h) in US Eastern Standard Time (EST); right $X$-axis number of calls $\mathrm{d}^{-1}$. Grey shading illustrates times between sunset and sunrise. Light blue shading indicates periods of missing data. Circles indicate the number of calls per hour

\section{Detector performance}

The truth data set consisted of 2428 manually selected minke whale pulse trains, which had been labeled from low signal quality (1) to high quality calls (4). The automated detector used in this analysis missed $0 \%$ (i.e. none) of the pulse trains labeled as Category $4(\mathrm{n}=54), 8 \%$ of Category $3(\mathrm{n}=415), 21 \%$ of Category $2(\mathrm{n}=1275)$ and $51 \%$ of Category $1(\mathrm{n}=$ 684). The overall false negative rate for this version of the detector was $27 \%$. The approximately $120 \mathrm{~h}$ of truthed data yielded 181 false positive detections.

\section{Seasonality and diel patterns}

A total of 8790 minke whale pulse trains were detected across the $3.5 \mathrm{yr}$ of 1 -channel recordings from the SBNMS. The detection of minke whale pulse trains was highly seasonal. Detections peaked during August and September, with 8639 (98\%) of events detected over the entire analysis period occur- ring from mid-July to mid-November. Fig. 5 illustrates the seasonal and diel patterns of pulse train occurrence. Detections generally increased over the month of August and peaked in September and October, with 7769 (88\%) of all detections from all years taking place during these 2 mo. No pulse trains were recorded during January or February of any year, and only a few detections were made from March to June. This strong seasonal pattern was repeated in all 3 full recording years $(2006,2008$ and 2009; Fig. 5).

Pulse train occurrence during the peak season (July to November) followed a very distinct diel pattern, with most detections recorded during the 'dark' period, from about 18:00 to 00:00 h EST (Figs. 5 \& 6). The mean number of calls per hour increased around twilight, and was highest around 19:00 EST and lowest during daylight hours (Fig. 6a). Hourly mean \pm SE adjusted values were $-1.47 \pm 0.08,-0.42 \pm 0.28$, $1.95 \pm 0.24$ for 'light', 'twilight' and 'dark' periods, respectively (Fig. 6b). Differences between means were statistically significant (Kruskal-Wallis test, $\chi^{2}=$ 

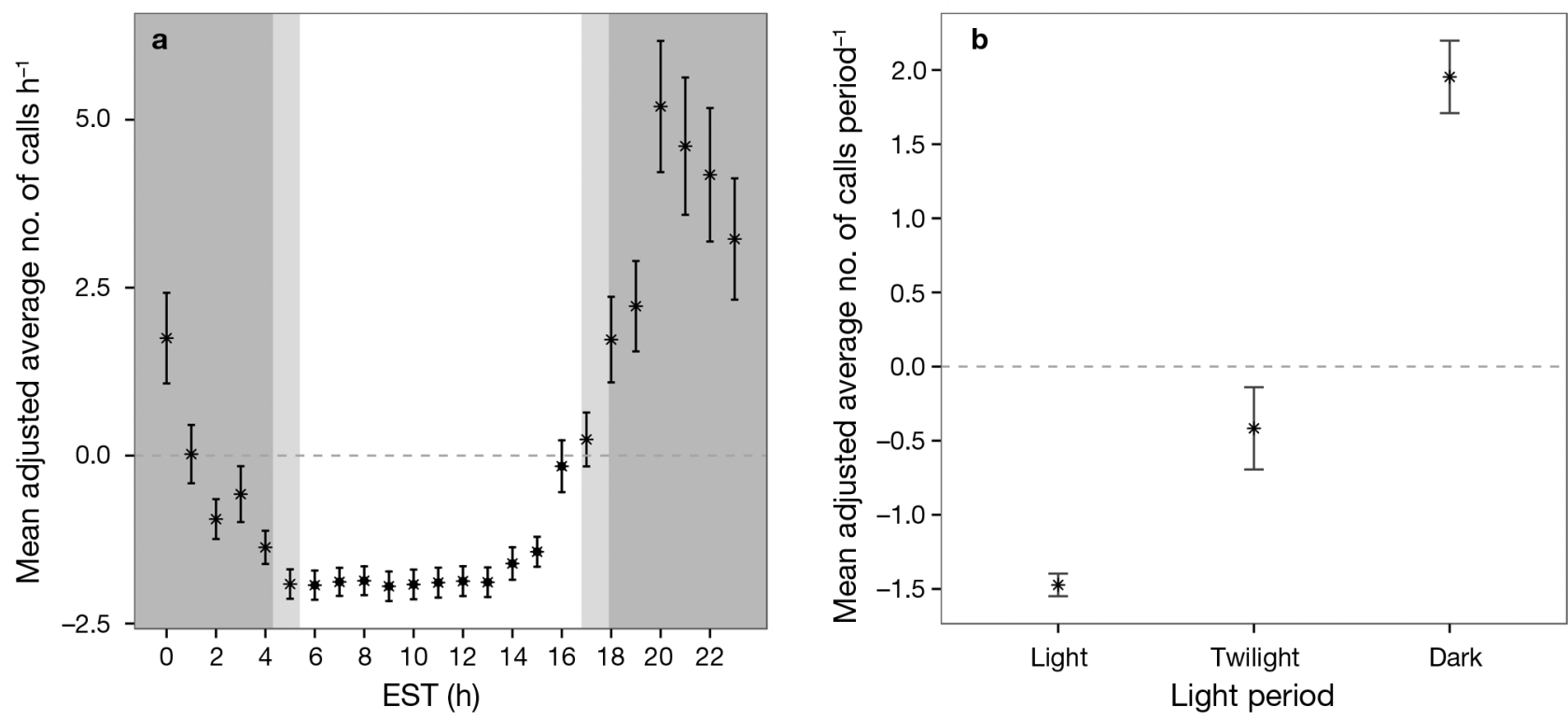

Fig. 6. (a) Mean \pm SE of minke whale pulse trains per hour over the course of a day. Dark gray shading indicates average dark hours and light gray shading represents twilight hours. (b) Mean \pm SE of minke whale pulse trains per light period, as determined by sun altitude. Light: $>0^{\circ}\left(\sim 05: 30\right.$ to $17: 00 \mathrm{~h}$ EST); twilight (nautical twilight): $\leq 0^{\circ}$ and $\geq-12^{\circ}(\sim 04: 30$ to $05: 30$ and $17: 00$ to $18: 00 \mathrm{~h} \mathrm{EST})$; dark: $<-12^{\circ}(\sim 18: 00$ to $04: 30 \mathrm{~h} \mathrm{EST})$. Diel analyses were based on data recorded from 15 July to 15 November 2006, 2008 and 2009

240.67, $\mathrm{df}=2, \mathrm{p}<0.0001$ ), and post-hoc comparisons between all pairs of means were significant at an alpha level of 0.001 .

\section{Spatial patterns}

From 15 July to 15 November 2006, 32029 minke whale pulse trains were recorded on 9 MARUs, deployed throughout SBNMS. Fig. 7 illustrates the spatial distribution of these detections by plots of circles with radii of approximately $15 \mathrm{~km}$ around the MARU's location. This representation incorporates a conservative detection range estimate for these calls based on preliminary source level data (D. Risch unpubl. data) and illustrates almost full range coverage of SBNMS, with some overlap between units. Since our main interest was in the relative spatial occurrence patterns, no adjustment for detection range overlap between units was performed in this analysis. Therefore, some pulse trains may have been detected on multiple units.

Although, pulse trains were detected across SBNMS, the majority of detections occurred in the eastern and southeastern parts of the sanctuary (Fig. 7). Overall, there were 120 detections/recording days on the most southeastern MARU, compared to a low of 5 detections/recording days at the most northern location.

\section{DISCUSSION}

Prior to this study, minke whale pulse trains in the North Atlantic were described most comprehensively from an area northeast of Puerto Rico by Mellinger et al. (2000), while Clark \& Gagnon (2004) described the seasonal occurrence of minke whale pulse trains in parts of the western North Atlantic. Although these authors could not visually confirm species identity, they concluded that the sounds they described were produced by minke whales, based on structural sound similarity to and geographic overlap of sample regions with Winn \& Perkins (1976). In their earlier study, Winn \& Perkins (1976) had been able to match acoustic recordings with visual observations of minke whales during several single species encounters in deeper waters of the Caribbean region. The present study is the first to describe long-term occurrence and distribution patterns of minke whale pulse trains in the western Gulf of Maine.

\section{Detector performance}

Minke whale pulse trains are structurally variable and their long signal durations frequently result in overlap in frequency and timing of vocal activity. In addition, they overlap with other baleen whale species, particularly humpback whales, communicat- 


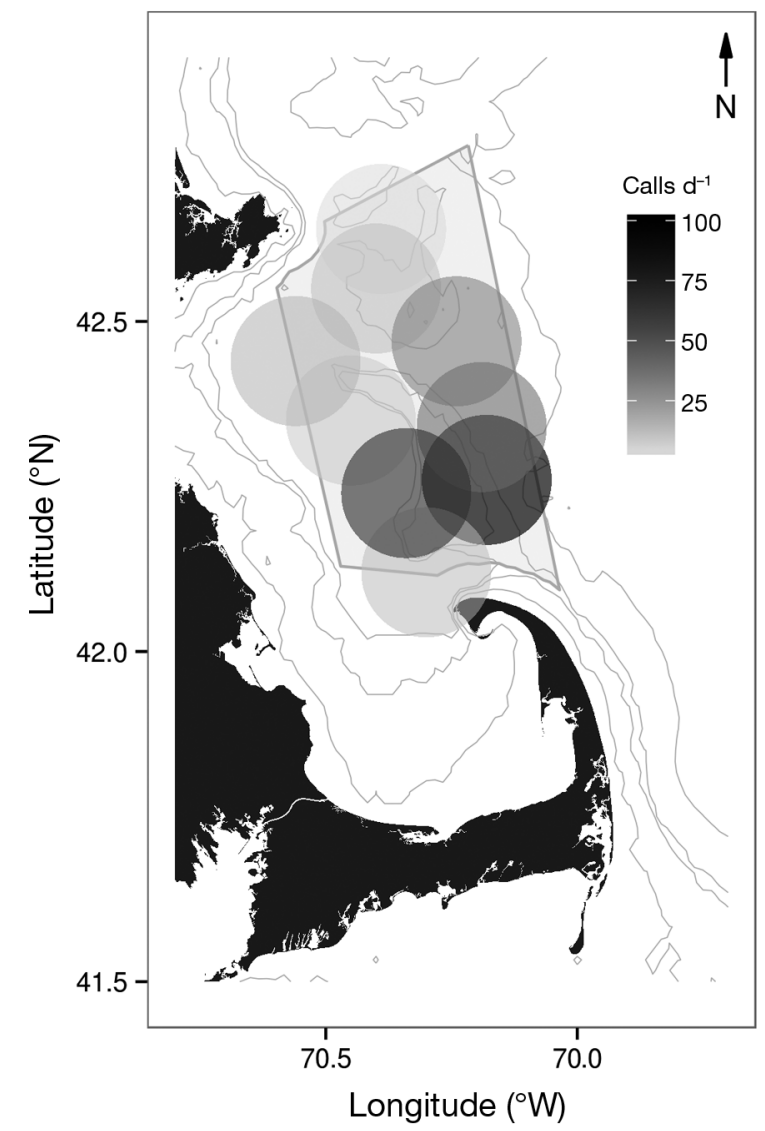

Fig. 7. Spatial distribution of minke whale pulse trains recorded throughout the Stellwagen Bank National Marine Sanctuary (SBNMS) from 15 July to 15 November 2006. Circles extend approximately $15 \mathrm{~km}$ in radius from marine autonomous recording unit (MARU) locations, and shadings reflect total number of recorded pulse trains per day, normalized by the number of recording days for each site

ing in a similar frequency range. These conditions, along with year-round high underwater noise levels, created a challenging acoustic scene for developing species-specific detectors for our study area. However, with an overall false negative rate of $27 \%$ (below $10 \%$ for strong signals), and a relatively low false positive rate, the pulse train detector used in this study served well for our broad-scale questions of seasonal, diel and spatial occurrence patterns.

\section{Classification and characterization}

In order to compare our data to Mellinger et al. (2000), we initially classified pulse trains according to their IPI structure. We then described further variability in the dataset using a combination of supervised random forests and cluster analysis in an effort to increase repeatability of our classification scheme.
The classification of the current dataset yielded 2 main categories: slow-down and constant pulse trains, with 3 sub-types each (Fig. 3). While Mellinger et al. (2000) described the first category, they did not describe the latter. Both types of signals have also been found and associated with minke whales in Onslow Bay, North Carolina, USA (Williams Hodge 2011). Additionally, in the Caribbean data analyzed by Mellinger et al. (2000), 100 out of 110 pulse trains were speed-up, while only 10 were slow-down pulse trains. In contrast, in the SBNMS dataset, only $2 \%$ of a $4 \mathrm{~d}$ sample $(\mathrm{n}=1068)$ were of this category. Instead, $60 \%$ of all calls in SBNMS were slow-down pulse trains.

These observed differences in minke whale vocal repertoire may be due to several reasons. First, the 2 datasets differed markedly in size and temporal scale. While Mellinger et al. analyzed $49 \mathrm{~h}$ of recordings, we explored $4 \mathrm{~d}$ of continuous acoustic data, collected over 2 different seasons. Since most of our detections occurred at night, while Mellinger et al. recorded mainly during the day, it is conceivable that the observed difference in vocal repertoire is due to a change in vocal repertoire from day- to nighttime. However, our data did not show any indication that this may be the case in our study area.

Second, since the majority of pulse trains recorded by Mellinger et al. were of low SNR, it is possible that the shorter constant pulse trains might have been missed. In addition, Mellinger et al. high-pass filtered their data at 100 to $200 \mathrm{~Hz}$. However, some constant pulse trains described in the current study have PFs between 55 and $61 \mathrm{~Hz}$ (e.g. c3; Table 1), and thus, differences in analysis bandwidth might also explain some disparities in vocal repertoire between studies. In this context it is noteworthy that Williams Hodge (2011) described the occasional association of constant pulse trains that match type c3, as described here, with high frequency clicks (PF $\sim 20 \mathrm{kHz}$ ). However, our recording bandwidth was too narrow to detect such high frequencies in our data.

Lastly, geographic variation in repertoire size or usage may be responsible for the observed differences. As a specific form of geographic variation, dialects are commonly defined as vocal variation between potentially interbreeding populations (Conner 1982) and have been shown to exist in several species of cetaceans (e.g. Ford 1991, Noad et al. 2000, Rendell \& Whitehead 2003). Dialects can arise due to genetic, environmental or social factors, including vocal learning. More simply, if vocal signals are associated with particular behaviors, vocal pro- 
duction may change with behavioral state, which in turn can vary by season and habitat (e.g. Oleson et al. 2007a, Van Parijs et al. 2009).

The behavioral function of minke whale pulse trains is currently unknown. However, it is conceivable that the observed differences in call type distribution might indicate a switch in activity from higher latitude summer feeding to presumed breeding at lower latitude winter grounds (Mitchell 1991, Van Waerebeek et al. 1999). This idea is further supported by structural differences between pulse trains recorded in SBNMS and those from the Caribbean, with the latter lasting about 20 s longer and exhibiting more than twice as many pulses per pulse train (Table 1; Mellinger et al. 2000). A correlation between call duration and arousal state has been demonstrated in some mammal species (Rendall 2003, Charlton et al. 2011). In several baleen whales only the males produce songs, which intensify during the breeding season and seem to play an important role in reproduction (e.g. Tyack 1981, Croll et al. 2002, Oleson et al. 2007b).

Dwarf minke whales wintering on the Great Barrier Reef have been shown to produce repetitive sequences of stereotypic 'star wars' vocalizations, which exhibit characteristics similar to reproductive displays found in other baleen whale species (Gedamke et al. 2001). However, it is currently unknown whether the 'star wars' calls, minke whale 'boings' from the North Pacific, or North Atlantic pulse trains are produced by only one sex or age class and which function they serve in the species' ecology (Gedamke et al. 2001, Oswald et al. 2011).

Thus, it is important to explore the behavioral significance of minke whale vocalizations and whether they may be gender or age specific. Such knowledge is particularly important when analyzing PAM data in the light of species distribution and density. Only part of a population may be successfully captured by monitoring sounds that are exclusively produced by a certain demographic. Minke whale migration in the North Atlantic appears to be segregated by sex, and females prefer higher latitudes during summer (e.g. Øien 1988, Laidre et al. 2009). If minke whale pulse trains are only produced by males, as shown for songs of other species, these sounds should be almost absent from these higher latitudes of the North Atlantic, where mainly females are present. Thus, depending on recording location, PAM data might produce very different results as a function of vocal behavior and/or demographic differences in distribution.

\section{Seasonality and diel patterns}

Our data show a strongly seasonal distribution of minke whale pulse trains in SBNMS, and the same general pattern was repeated in 3 separate years (Fig. 5). Pulse trains increased in abundance in July, peaked in September and October and decreased again in December. No detections were made during January and February, and only a few detections were recorded from March to June. This seasonality may either indicate the absence of minke whales from the area at times of the year when they are not recorded, a switch in sex ratio, if vocalizations are gender specific, or a change in behavior. While the first 2 explanations would indicate seasonal movement, the latter would allow for year-round site fidelity, both of which have been reported to exist in minke whales from different areas of the North Atlantic and are not mutually exclusive (Macleod et al. 2004, Bartha et al. 2011).

Visual sightings data from this area support the seasonal movement hypothesis. Year-round data (Murphy 1995), collected over a period of 13 consecutive years in Massachusetts Bay, including SBNMS, show a striking similarity to the pulse train occurrence patterns reported here. In over a decade of observations in this area, no minke whales were sighted in the months of January and February, and a distinct peak in occurrence was observed to start in July, increasing through September and decreasing in November. The combined visual and acoustic data therefore suggest the absence of minke whales from Massachusetts waters during winter, a limited occurrence during spring and summer and a directed movement into this area in autumn.

Minke whales in the North Atlantic are widely distributed across summer feeding grounds north of $50^{\circ} \mathrm{N}$, which range from Newfoundland-Labrador to Greenland, Iceland and northern Norway, and extend into the Barents and North Seas (e.g. Horwood 1990, Andersen et al. 2003). SBNMS might therefore be a transitory location for minke whales migrating along the US and Canadian east coasts. The relative strong peak in vocal abundance in autumn compared to the spring would suggest a more offshore occurrence of this species on their northbound migration and a more coastal distribution later in the year, when the whales are headed south.

A greater abundance of minke whales in coastal waters in September and October might also be related to the distribution of their prey. Humpback and fin whales visit Massachusetts waters around 
Stellwagen Bank during summer to feed on sandlance Ammodytes spp. (e.g. Overholtz \& Nicolas 1979, Friedlaender et al. 2009). Sandlance, as well as herring and other small shoaling fish, are an important prey for minke whales in the North Atlantic (e.g. Haug et al. 1995, Lindstrøm et al. 2002, Anderwald et al. 2012). Although she observed only little surface feeding activity, Murphy (1995) suggested Massachusetts Bay as a possible feeding ground also for minke whales, citing the notable absence of minke whales during a crash of the local sandlance population in the mid-1980s (Payne et al. 1990, Murphy 1995).

Recent work on humpback whale song provides evidence for widespread occurrence of song on feeding grounds and outside the traditional breeding season (e.g. Stimpert et al. 2012, Vu et al. 2012), as well as on migration routes (e.g. Charif et al. 2001). Similarly, fin whale song has been shown to persist on feeding grounds much later in the year than previously thought (e.g. Simon et al. 2010, Morano et al. 2012). In both species it has been shown that only males sing and that songs serve in a mating context (Tyack 1981, Glockner 1983, Croll et al. 2002). Studies on changes in sex hormones in North Atlantic minke whales have shown a rise in blood testosterone levels in adult males and progesterone levels in females during the feeding season (Kjeld et al. 2004). Thus, if minke whale pulse trains were to serve in a mating context, their occurrence on migration and on a potential feeding ground is consistent with the behavioral flexibility observed in other baleen whales, as well as observed hormonal changes at the end of their summer feeding period. In addition, if minke whale pulse trains were to serve in a mating context, their occurrence on a potential feeding ground is consistent with observed hormonal changes at the end of their summer feeding period.

Minke whale pulse trains exhibited diel periodicity, with calling rates being lowest during light and peaking during dark periods. Without more knowledge on individual calling rates, the reason for the observed diel pattern cannot be conclusively resolved. It may be the result of higher individual calling rates, an increase of the overall number of vocalizing individuals at night or a change of animal abundance from day- to nighttime.

Diel variation in calling rates has been observed in several other baleen whale species and may vary by species and/or habitat. Sei whales in the Gulf of Maine and right whales on Emerald Bank, Nova Scotia, Canada, exhibited higher calling rates during the day (Mellinger et al. 2007b, Baumgartner \& Fratan- toni 2008). In contrast, right whales in the Pacific and the Gulf of Maine (Matthews et al. 2001,Wiggins et al. 2005, Munger et al. 2008, Mussoline et al. 2012) showed increased calling activity at nighttime and both blue and humpback whales have been shown to increase singing activity at night (Au et al. 2000, Stafford et al. 2005). For signals that serve in a reproductive context, such as humpback whale song, an increase in nighttime vocal activity might be related to the lack of visual cues for advertising and competitive display behavior (Au et al. 2000). In addition, calling could be directly or inversely related to feeding activity. Vocalizations might be used to advertise resources and thus be a proxy for feeding behavior (Croll et al. 2002, Stafford et al. 2005). On the other hand, if calls are generally serving in a social context, higher vocalization rates would be expected when whales are not actively feeding. Such a relationship has been suggested for right and sei whales, which, in some areas, show higher calling rates during the day, when their primary prey, Calanus finmarchicus, is aggregated at depth and thus less accessible (Mellinger et al. 2007b, Baumgartner \& Fratantoni 2008). The behavioral context of minke whale vocalizations in SBNMS is currently unknown, but if the diel pattern observed here is related to feeding activity, an inverse relationship would suggest that minke whales feed primarily during the day and either advertise resources or spend more time socializing at night.

In the North Pacific, minke whale 'boing' rates recorded in Hawaii, USA, did not show a significant diel pattern (Oswald et al. 2011). In contrast to SBNMS, Hawaii is likely not a feeding area for minke whales but serves more likely as a breeding ground for the species (Oswald et al. 2011). Therefore, although the behavioral contexts are not completely understood for either area, the strong diel pattern recorded here might indicate that the direct or indirect relationship between vocalizations and presumed feeding behavior is stronger than the influence of light on visual-acoustic displays in a primarily reproductive context.

\section{Spatial patterns}

The spatial distribution of minke whale pulse trains in 2006 suggests that minke whales prefer the deeper waters to the east of Stellwagen Bank. On their summer feeding grounds, minke whales in the North Atlantic are commonly found close to shore (e.g. Macleod et al. 2004, Bartha et al. 2011, Anderwald et 
al. 2012). However, despite fairly consistent visual monitoring efforts for other species in the southeastern United States (e.g. Keller et al. 2012), there are large data gaps concerning the winter distribution and migratory routes of this species in the North Atlantic. This lack of data, even including opportunistic observations, suggests a more offshore distribution during winter and spring. In support of this hypothesis, recent satellite tracking data show the southbound migration of individuals summering around Iceland to take place in the middle of the North Atlantic (Víkingsson \& Heide-Jørgensen 2012). In addition, in the western North Atlantic, visual sightings data from North Carolina and Florida, USA, found minke whales offshore of the continental shelf in the winter time (Nilsson et al. 2011). The spatio-temporal pattern of sporadic vocalizations in spring and a peak in vocal abundance to the east of SBNMS in autumn, is consistent with the idea of Massachusetts Bay serving as part of the migration corridor for minke whales. A potentially more inshore distribution, and therefore higher acoustic detection rate on the southbound migration, may be related to the distribution of their prey at this time of year. However, more data on prey distribution, the feeding behavior and individual movement patterns of minke whales in the Gulf of Maine are needed to draw final conclusions.

\section{CONCLUSION}

Little is known about the abundance and distribution of North Atlantic minke whales outside their known summer feeding habitats, where they are still hunted commercially in soma areas. This study documents their seasonal occurrence in Massachusetts waters and shows that PAM can be used successfully to monitor and describe this species' vocalizations. The lack of data on minke whale migration patterns and winter habitats is likely due to an offshore distribution of the species during winter and spring. Thus, because of its potential for monitoring remote areas, independent of weather conditions PAM data will be crucial in our future understanding of important minke whale habitat. However more concurrent visual and acoustic data sampling is needed to interpret such data better, particularly when trying to determine whether an absence of acoustic detections can be interpreted as species absence or not. In addition, future work is needed on the behavioral context of known minke whale vocalizations, including caller identity, source levels and calling rates, as well as the description of the full vocal repertoire for the species. Understanding the basic acoustic ecology will provide a better understanding of the year-round spatio-temporal distribution of North Atlantic minke whales. In turn, these data will help to predict important speciesspecific habitat and ultimately identify and mitigate potential threats to the species, particularly in areas where they have not been monitored traditionally.

Acknowledgements. Parts of this work were funded by NOAA's Northeast Fisheries Science Center, Northeast Regional Office, and NOAA's Stellwagen Bank National Marine Sanctuary (SBNMS). It was supported by an Office of Naval Research grant (number N00014-07-1-1029) awarded by the National Oceanographic Partnership Program. We thank D. Arch, D. Cholewiak, H. Figueroa, M. Fowler, L. Hatch, C. Muirhead, A. Murray, S. Mussoline, S. Kibner, W. Krkoska, J. Stanistreet, C. Tesseglia-Hymes, M. Thompson, C. Tremblay, B. Wallace, J. Walluk, A. Warde, F. Wenzel, D. Wiley and E. Vu for help with various stages of fieldwork and data processing. In addition, many thanks to everyone at the Bioacoustic Research Program, Cornell Laboratory of Ornithology and the SBNMS for their support over the years. Thanks to M. Soldevilla and M. Pourhomayoun for help with figure production. We thank D. Cholewiak, M. Simpkins and 3 anonymous reviewers, who significantly improved the quality of this manuscript by providing insightful comments.

\section{LITERATURE CITED}

Andersen L, Born E, Dietz R, Haug T, Øien N, Bendixen C (2003) Genetic population structure of minke whales Balaenoptera acutorostrata from Greenland, the North East Atlantic and the North Sea probably reflects different ecological regions. Mar Ecol Prog Ser 247:263-280

Anderwald P, Daníelsdóttir AK, Haug T, Larsen F and others (2011) Possible cryptic stock structure for minke whales in the North Atlantic: implications for conservation and management. Biol Conserv 144:2479-2489

Anderwald P, Evans P, Dyer R, Dale A, Wright P, Hoelzel A (2012) Spatial scale and environmental determinants in minke whale habitat use and foraging. Mar Ecol Prog Ser 450:259-274

Au WWL, Mobley J, Burgess WC, Lammers MO, Nachtigall PE (2000) Seasonal and diurnal trends of chorusing humpback whales wintering in waters off western Maui. Mar Mamm Sci 16:530-544

Barlow J, Taylor BL (2005) Estimates of sperm whale abundance in the northeastern temperate Pacific from a combined acoustic and visual survey. Mar Mamm Sci 21: 429-445

Bartha GB, Gowans S, Simard P, Tetley M, Keith EO (2011) Population size and site fidelity of North Atlantic minke whales (Balaenoptera acutorostrata acutorostrata) off the Atlantic coast of Nova Scotia, Canada. Aquat Mamm 37: 454-463

Baumgartner MF, Fratantoni DM (2008) Diel periodicity in both sei whale vocalization rates and the vertical migration of their copepod prey observed from ocean gliders. Limnol Oceanogr 53:2197-2209 
Beamish P, Mitchell E (1973) Short pulse length audio frequency sounds recorded in the presence of a minke whale (Balaenoptera acutorostrata). Deep-Sea Res Oceanogr Abstr 20:375-386

$>$ Benjamins S, Ledwell W, Huntington J, Davidson AR (2012) Assessing changes in numbers and distribution of large whale entanglements in Newfoundland and Labrador, Canada. Mar Mamm Sci 28:579-601

Breiman L, Friedman J, Olshen R, Stone C (1984) Classification and regression trees. Wadsworth, Belmont, CA

$>$ Calupca T, Fristrup KM, Clark C (2000) A compact digital recording system for autonomous bioacoustic monitoring. J Acoust Soc Am 108:2582

Charif RA, Clapham PJ, Clark CW (2001) Acoustic detections of singing humpback whales in deep waters off the British Isles. Mar Mamm Sci 17:751-768

> Charlton BD, Keating JL, Kersey D, Rengui L, Huang Y, Swaisgood RR (2011) Vocal cues to male androgen levels in giant pandas. Biol Lett 7:71-74

Clark CW, Ellison WT (2004) Potential use of low-frequency sounds by baleen whales for probing the environment: evidence from models and empirical measurements. In Thomas JA, Moss CF, Vater M (eds) Echolocation in bats and dolphins. University of Chicago Press, Chicago, IL, p 604

Clark CW, Gagnon GJ (2004) Low-frequency vocal behaviors of baleen whales in the North Atlantic: insights from integrated undersea surveillance system detections, locations, and tracking from 1992 to 1996. US Navy J Underw Acoust 52:609-640

> Conner DA (1982) Dialects vs geographic variation in mammalian vocalizations. Anim Behav 30:297-298

> Croll DA, Clark CW, Acevedo A, Tershy B, Flores S, Gedamke J, Urban J (2002) Only male fin whales sing loud songs. Nature 417:809

Cutler DR, Edwards TC, Beard KH, Cutler A, Hess KT, Gibson J, Lawler JJ (2007) Random forests for classification in ecology. Ecology 88:2783-2792

> Davidson AD, Boyer AG, Kim H, Pompa-Mansilla S and others (2012) Drivers and hotspots of extinction risk in marine mammals. Proc Natl Acad Sci USA 109:3395-3400

> de Boer M (2010) Spring distribution and density of minke whale Balaenoptera acutorostrata along an offshore bank in the central North Sea. Mar Ecol Prog Ser 408: 265-274

Dugan PJ, Ponirakis DW, Zollweg JA, Pitzrick MS and others (2011) SEDNA - bioacoustic analysis toolbox: Matlab platform to support high performance computing, noise analysis, event detection and event modeling. Proc IEEE OCEANS 2011, 19-22 September, 2011, Waikoloa, HI, p 1-10

$>$ Edds-Walton PL (2000) Vocalizations of minke whales Balaenoptera acutorostrata in the St. Lawrence Estuary. Bioacoustics 11:31-50

Figueroa HK, Robbins M (2008) XBAT: An open-source extensible platform for bioacoustic research and monitoring. In: Frommolt K, Bardeli R, Clausen M (eds) Computational bioacoustics for assessing biodiversity. Bundesamt für Naturschutz, Bonn, p 143-155

Ford JKB (1991) Vocal traditions among resident killer whales (Orcinus orca) in coastal waters of British Columbia. Can J Zool 69:1454-1483

Fraley C, Raftery AE (2010) MCLUST Version 3 for R: normal mixture modeling and model-based clustering Technical report no. 504, Department of Statistics, Uni- versity of Washington, WA

Friedlaender A, Hazen E, Nowacek D, Halpin P and others (2009) Diel changes in humpback whale Megaptera novaeangliae feeding behavior in response to sand lance Ammodytes spp. behavior and distribution. Mar Ecol Prog Ser 395:91-100

> Gaines BR, Compton P (1995) Induction of ripple-down rules applied to modeling large databases. J Intell Inf Syst 5: 211-228

- Gallus A, Dähne M, Verfuß UK, Bräger S, Adler S, Siebert U, Benke H (2012) Use of static passive acoustic monitoring to assess the status of the 'Critically Endangered' Baltic harbour porpoise in German waters. Endang Species Res 18:265-278

Gedamke J, Costa D, Dunstan A (2001) Localization and visual verification of a complex minke whale vocalization. J Acoust Soc Am 109:3038-3047

Glockner D (1983) Determining the sex of humpback whales (Megaptera novaeangliae) in their natural environment. In: Payne RS (ed) Communication and behavior of whales. Westview Press, Boulder, CO, p 447-464

Halpern BS, Walbridge S, Selkoe KA, Kappel CV and others (2008) A global map of human impact on marine ecosystems. Science 319:948-952

Hatch L, Clark C, Merrick R, van Parijs S and others (2008) Characterizing the relative contributions of large vessels to total ocean noise fields: a case study using the Gerry E. Studds Stellwagen Bank National Marine Sanctuary. Environ Manag 42:735-752

Hatch LT, Clark C, van Parijs S, Frankel A, Ponirakis D (2012) Quantifying loss of communication space for right whales in and around a U.S. National Marine Sanctuary. Conserv Biol 26:983-994

Haug T, Gjosaeter H, Lindstrom U, Nilssen K (1995) Diet and food availability for north-east Atlantic minke whales (Balaenoptera acutorostrata), during the summer of 1992. ICES J Mar Sci 52:77

Horwood J (1990) Biology and exploitation of the minke whale. CRC Press, Boca Raton, FL

Jackson DA, Walker SC, Poos MS (2010) Cluster analysis of fish community data: 'new' tools for determining meaningful groupings of sites and species assemblages. Am Fish Soc Symp 73:503-527

Kaufman L, Rousseeuw PJ (1990) Finding groups in data: an introduction to cluster analysis. Wiley, New York, NY

Keller CA, Garrison L, Baumstark R, Ward-Geiger L, Hines E (2012) Application of a habitat model to define calving habitat of the North Atlantic right whale in the southeastern United States. Endang Species Res 18:73-87

Kjeld M, Alfredsson Á, Ólafsson Ö, Tryland M, Christensen I, Stuen S, Árnason A (2004) Changes in blood testosterone and progesterone concentrations of the North Atlantic minke whale (Baleanoptera acutorostrata) during the feeding season. Can J Fish Aquat Sci 61:230-237

Laidre KL, Heagerty PJ, Heide-Jørgensen MP, Witting L, Simon M (2009) Sexual segregation of common minke whales (Balaenoptera acutorostrata) in Greenland, and the influence of sea temperature on the sex ratio of catches. ICES J Mar Sci 66:2253-2266

Leatherwood S, Thomas JA, Awbrey FT (1981) Minke whales off northwestern Ross Island. Antarct J US 16: 154-156

Lewin-Koh NJ, Bivand R (2012) Maptools: tools for reading and handling spatial objects. $\mathrm{R}$ package version 0.8-20. www.maptools.r-forge.r-project.org 
Lewis T, Gillespie D, Lacey C, Matthews J and others (2007) Sperm whale abundance estimates from acoustic surveys of the Ionian Sea and Straits of Sicily in 2003. J Mar Biol Assoc UK 87:353-357

> Lindstrøm U, Haug T, Røttingen I (2002) Predation on herring, Clupea harengus, by minke whales, Balaenoptera acutorostrata, in the Barents Sea. ICES J Mar Sci 59: $58-70$

> Macleod K, Fairbairns R, Gill A, Fairbairns B, Gordon J, Blair-Myers C, Parsons E (2004) Seasonal distribution of minke whales Balaenoptera acutorostrata in relation to physiography and prey off the Isle of Mull, Scotland. Mar Ecol Prog Ser 277:263-274

Maechler M, Rousseeuw P, Struyf A, Hubert M, Hornik K (2012) Cluster: cluster analysis basics and extensions. R package version 1.14.2. www.cran.r-project.org/web/ packages/cluster/index.html

> Marques TA, Thomas L, Martin SW, Mellinger DK and others (2010) Spatially explicit capture-recapture methods to estimate minke whale density from data collected at bottom-mounted hydrophones. J Ornithol 152:445-455

Marques TA, Thomas L, Martin SW, Mellinger DK and others (2013) Estimating animal population density using passive acoustics. Biol Rev Camb Philos Soc 88(2): 287-309

> Martin SW, Marques TA, Thomas L, Morrissey RP and others (2013) Estimating minke whale (Balaenoptera acutorostrata) boing sound density using passive acoustic sensors. Mar Mamm Sci 29:142-158

Matthews JN, Brown S, Gillespie D, Johnson MP and others (2001) Vocalisation rates of the North Atlantic right whale (Eubalaena glacialis). J Cetacean Res Manag 3: 271-282

McComb K, Reby D (2005) Vocal communication networks in large terrestrial animals. In: McGregor PK (ed) Animal communication networks. Cambridge University Press, Cambridge, p 373

- Mellinger D, Carson C, Clark C (2000) Characteristics of minke whale (Balaenoptera acutorostrata) pulse trains recorded near Puerto Rico. Mar Mamm Sci 16:739-756

Mellinger DK, Stafford KM, Moore SE, Dziak RP, Matsumoto H (2007a) An overview of fixed passive acoustic observation methods for cetaceans. Oceanography (Wash DC) 20:36-45

- Mellinger DK, Nieukirk SL, Matsumoto H, Heimlich SL and others (2007b) Seasonal occurrence of North Atlantic right whale (Eubalaena Glacialis) vocalizations at two sites on the Scotian Shelf. Mar Mamm Sci 23:856-867

Mitchell ED Jr. (1991) Winter records of the minke whale (Balaenoptera acutorostrata acutorostrata Lacépède 1804) in the southern North Atlantic. Rep Int Whaling Comm 41:455-457

> Moore SE, Stafford KM, Mellinger DK, Hildebrand JA (2006) Listening for large whales in the offshore waters of Alaska. Bioscience 56:49-55

Morano JL, Salisbury DP, Rice AN, Conklin KL, Falk KL, Clark CW (2012) Seasonal and geographical patterns of fin whale song in the western North Atlantic Ocean. J Acoust Soc Am 132:1207-1212

Munger LM, Wiggins SM, Moore SE, Hildebrand JA (2008) North Pacific right whale (Eubalaena japonica) seasona and diel calling patterns from long-term acoustic recordings in the southeastern Bering Sea, 2000-2006. Mar Mamm Sci 24:795-814

Murphy M (1995) Occurrence and group characteristics of minke whales, Balaenoptera acutorostrata, in Massachusetts Bay and Cape Cod Bay. Fish Bull 93:577-585

Mussoline S, Risch D, Clark C, Hatch L and others (2012) Seasonal and diel variation in North Atlantic right whale up-calls: implications for management and conservation in the northwestern Atlantic Ocean. Endang Species Res $17: 17-26$

Nilsson P, Cummings E, Foley H, Hardee R and others (2011) Recent winter sightings of minke whales (Balaenoptera acutorostrata) in the South Atlantic Bight. Abstr 19th Bienn Conf Biol Mar Mamm, Tampa, FL

Noad MJ, Cato DH, Bryden MM, Jenner MN, Jenner KCS (2000) Cultural revolution in whale songs: humpbacks have picked up a catchy tune sung by immigrants from a distant ocean. Nature 408:537

Øien N (1988) Length distributions in catches from the north-eastern Atlantic stock of minke whales. Rep Int Whaling Comm 38:289-295

Oleson E, Wiggins S, Hildebrand J (2007a) Temporal separation of blue whale call types on a southern California feeding ground. Anim Behav 74:881-894

Oleson EM, Calambokidis J, Burgess WC, Mcdonald MA, LeDuc CA, Hildebrand JA (2007b) Behavioral context of call production by eastern North Pacific blue whales. Mar Ecol Prog Ser 330:269-284

Oswald JN, Au WWL, Duennebier F (2011) Minke whale (Balaenoptera acutorostrata) boings detected at the Station ALOHA Cabled Observatory. J Acoust Soc Am 129: 3353-3360

Overholtz W, Nicolas J (1979) Apparent feeding by the fin whale (Balaenoptera physalus) and humpback whale (Megaptera novaeangliae), on the American sand lance (Ammodytes americanus), in the northwest Atlantic. Fish Bull 77:285-287

Parks S, Searby A, Célérier A, Johnson M, Nowacek D, Tyack P (2011) Sound production behavior of individual North Atlantic right whales: implications for passive acoustic monitoring. Endang Species Res 15:63-76

Payne PM, Wiley DN, Young SB, Pittman S, Clapham PJ, Jossi JW (1990) Recent fluctuations in the abundance of baleen whales in the southern Gulf of Maine in relation to changes in selected prey. Fish Bull 88:687-696

Popescu M, Dugan PJ, Pourhomayoun M, Risch D, Lewis III HW, Clark CW (2013) Bioacoustical periodic pulse train signal detection and classification using spectrogram intensity binarization and energy projection. ICML 2013 Workshop on Machine Learning for Bioacoustics, Atlanta GA

Rankin S, Barlow J (2005) Source of the North Pacific 'boing' sound attributed to minke whales. J Acoust Soc Am 118: 3346-3351

Rankin S, Norris TF, Smultea MA, Oedekoven C, Zoidis AM, Silva E, Rivers J (2007) A visual sighting and acoustic detections of minke whales, Balaenoptera acutorostrata (Cetacea: Balaenopteridae), in nearshore Hawaiian waters. Pac Sci 61:395-398

Reilly SB, Bannister JL, Best PB, Brown M and others (2008) IUCN Red List of Threatened Species. Version 2011.2. www.iucnredlist.org

Rendall D (2003) Acoustic correlates of caller identity and affect intensity in the vowel-like grunt vocalizations of baboons. J Acoust Soc Am 113:3390-3402

Rendell LE, Whitehead H (2003) Vocal clans in sperm whales (Physeter macrocephalus). Proc Biol Sci 270: 225-231 
Risch D, Corkeron PJ, Ellison WT, van Parijs SM (2012) Changes in humpback whale song occurrence in response to an acoustic source $200 \mathrm{~km}$ away. PLoS ONE $7: \mathrm{e} 29741$

Robards M, Reeves RR (2011) The global extent and character of marine mammal consumption by humans: 19702009. Biol Conserv 144:2770-2786

Rousseeuw PJ (1987) Silhouettes: a graphical aid to the interpretation and validation of cluster analysis. J Comput Appl Math 20:53-65

Schevill WE, Watkins WA (1972) Intense low-frequency sounds from an Antarctic minke whale, Balaenoptera acutorostrata. Breviora 388:1-7

Simon M, Stafford KM, Beedholm K, Lee CM, Madsen PT (2010) Singing behavior of fin whales in the Davis Strait with implications for mating, migration and foraging. J Acoust Soc Am 128:3200-3210

> Skaug H, Øien N, Schweder T, Bøthun G (2004) Abundance of minke whales (Balaenoptera acutorostrata) in the northeast Atlantic: variability in time and space. Can J Fish Aquat Sci 61:870-886

Stafford K, Moore S, Fox C (2005) Diel variation in blue whale calls recorded in the eastern tropical Pacific. Anim Behav 69:951-958

Stimpert AK, Wiley DN, Au WWL, Johnson MP, Arsenault R (2007) 'Megapclicks': acoustic click trains and buzzes produced during night-time foraging of humpback whales (Megaptera novaeangliae). Biol Lett 3:467-470

Stimpert AK, Peavey LE, Friedlaender AS, Nowacek DP (2012) Humpback whale song and foraging behavior on an Antarctic feeding ground. PLoS ONE 7:e51214

Strobl C, Boulesteix A, Kneib T, Augustin T, Zeileis A (2008) Conditional variable importance for random forests. BMC Bioinformatics 9:307

Strobl C, Malley J, Tutz G (2009) An introduction to recursive partitioning: rationale, application, and characteristics of classification and regression trees, bagging, and random forests. Psychol Methods 14:323-348

Struyf A, Hubert M, Rousseeuw P (1996) Clustering in an object-oriented environment. J Stat Softw 1:1-30

Editorial responsibility: Per Palsböll,

Groningen, Netherlands
Tyack P (1981) Interactions between singing Hawaiian humpback whales and conspecifics nearby. Behav Ecol Sociobiol 8:105-116

Tyack PL, Clark CW (2000) Communication and acoustic behavior of dolphins and whales. In: Au WWL, Popper NA, Fay RR (eds) Hearing by whales and dolphins. Springer, New York, NY, p 156-224

Van Parijs S, Clark C, Sousa-Lima R, Parks S, Rankin S, Risch D, van Opzeeland I (2009) Management and research applications of real-time and archival passive acoustic sensors over varying temporal and spatial scales. Mar Ecol Prog Ser 395:21-36

Van Waerebeek K, André $M$, Sequeria M, Vidal $M$ and others (1999) Spatial and temporal distribution of the minke whale, Balaenoptera acutorostrata (Lacépède 1804), in the southern northeast Atlantic Ocean and the Mediterranean Sea, with reference to stock identity. J Cetacean Res Manag 1:223-237

Víkingsson GA, Heide-Jørgensen MP (2012) Migration and local movements of common minke whales tracked by satellite in the North Atlantic during 2001-2010. IWC (International Whaling Commission) SC F13(SP18): $1-11$

Vu ET, Risch D, Clark CW, Gaylord S and others (2012) Humpback whale song occurs extensively on feeding grounds in the western North Atlantic Ocean. Aquat Biol 14:175-183

Waring GT, Josephson E, Maze-Foley K, Rosel PE (2012) U.S. Atlantic and Gulf of Mexico marine mammal stock assessments: 2011. NOAA Tech Memo NMFS NE 221

Wiggins S, Oleson E, McDonald M, Hildebrand J (2005) Blue whale (Balaenoptera musculus) diel call patterns offshore of southern California. Aquat Mamm 31: 161-168

Williams Hodge L (2011) Monitoring marine mammals in Onslow Bay, North Carolina, using passive acoustics. PhD Thesis, Duke University, Durham, NC

Winn HE, Perkins PJ (1976) Distribution and sounds of the minke whale, with a review of mysticete sounds. Cetology 19:1-11

Submitted: February 8, 2013; Accepted: May 29, 2013

Proofs received from author(s): August 18, 2013 